\title{
Review on Opinion Mining for Fully Fledged System
}

\author{
Asmita Dhokrat ${ }^{\star}$, Sunil Khillare, C Namrata Mahender \\ Dept. of Computer Science and IT, Dr. Babasaheb Ambedkar Marathwada University \\ Aurangabad, Maharashtra-431001, India \\ ${ }^{*}$ Corresponding author, e-mail: asmita.dhokrat@gmail.com
}

\begin{abstract}
Humans communication is generally under the control of emotions and full of opinions. Emotions and their opinions plays an important role in thinking process of mind, influences the human actions too. Sentiment analysis is one of the ways to explore user's opinion made on any social media and networking site for various commercial applications in number of fields. This paper takes into account the basis requirements of opinion mining to explore the present techniques used to develop a fully fledged system. Is highlights the opportunities or deployment and research of such systems. The available tools used for building such applications have even presented with their merits and limitations.
\end{abstract}

Keywords: Opinion Mining, Emotion, Sentiment Analysis

\section{Introduction}

Emotions are the complex state of feelings that results in physical and emotional changes that influences our behavior. Emotion is a subjective, conscious experience characterized mainly by psycho-physiological expressions, biological reactions, and mental states. Emotion is often associated and considered commonly significant with mood, nature, personality, disposition, and motivation. It is also influenced by hormones and neurotransmitters such as dopamine, noradrenaline, serotonin, oxytocin, cortisol and GABA [1]. Emotion is a positive or negative experience that is associated with a particular pattern of physiological activity. Humans carry lot of emotions like happiness, sadness, angry, disgust, surprise, fear, panic, scared etc. identifying these emotions are very easy in face to face communication compare to written communication. But now a day's use of social media has increased rapidly and the huge amount of textual data became available on web, mining and managing this vast data has become a crucial task. As the growth of E-facilities have increased lots of people got encouraged to write their emotions, views, opinions about a person, product, place or anything they want.

Opinion Mining or Sentiment analysis involves building a system to explore user's opinions made in blog posts, comments, reviews or tweets, about the product, policy or a topic [2]. Opinion mining is nothing but finding the opinion of person from sentences and classify them on the basis of polarity. As the world changed into E-World the way of expression has dramatically changed for example wide use of smiley's and symbols can be seen as expression while texting. Social communication can be observed on internet and new term has been coined for various ways of communication like texting, twitting, posting etc. people like to communicate with others through internet, they want to share their feelings, likes, dislikes, opinions, views, reviews, emotions etc. people are happy to share their personal life via social media, the use of social media has increased so much and so rapidly that even no body worries about what they are sharing and is this good to share our personal life with unknown persons? Is there any need to share our photos, videos or our daily activities on internet? So finding the sentiment, emotion behind this activity is also an important task for understanding the psycho-socio status. So from that text, mining the opinions of people and finding their views, reaction, sentiments and emotions have become challenging task.

Opinion Mining is the field of study that analyzes people's opinion, sentiments, evaluations, attitudes and emotions from written text. Opinion Mining is one of the most active research areas in Natural Language Processing and is also widely studied in data mining, web mining and text mining this research has spread outside of computer science to the management science and social science due to its importance to business and society. The 
growing importance of sentiment analysis coincides with the growth of social media such as Reviews, Forums, discussion groups, chatting, blogs, micro-blogs, twitter and social networks.

\subsection{Categorization of Text}

Sentiment analysis is also called as opinion mining; as it mines the information from various text forms such as reviews, news \& blogs and classifies them on the basis of their polarity as positive, negative or neutral [3]. It focuses on categorizing the text at the level of subjective and objective nature. Subjectivity indicates that the text contains/bears opinion content for e.g. Battery life of Samsung mobiles are good. (This sentence has an opinion, it talks about the Samsung mobile phones and showing positive (good) opinion hence it is Subjective). Samsung mobiles are having long battery life. (This sentence is a fact, general information rather than an opinion or a view of some individual and hence its objective) [4].

\subsection{Components of Opinion Mining}

There are mainly three components of Opinion Mining [3]:

- Opinion Holder: Opinion holder is the holder of a particular opinion; it may be a person or an organization that holds the opinion. In the case of blogs and reviews, opinion holders are those persons who write these reviews or blogs.

- Opinion Object: Opinion object is an object on which the opinion holder is expressing the opinion.

- Opinion Orientation: Opinion orientation of an opinion on an object determines whether the opinion of an opinion holder about an object is positive, negative or neutral.

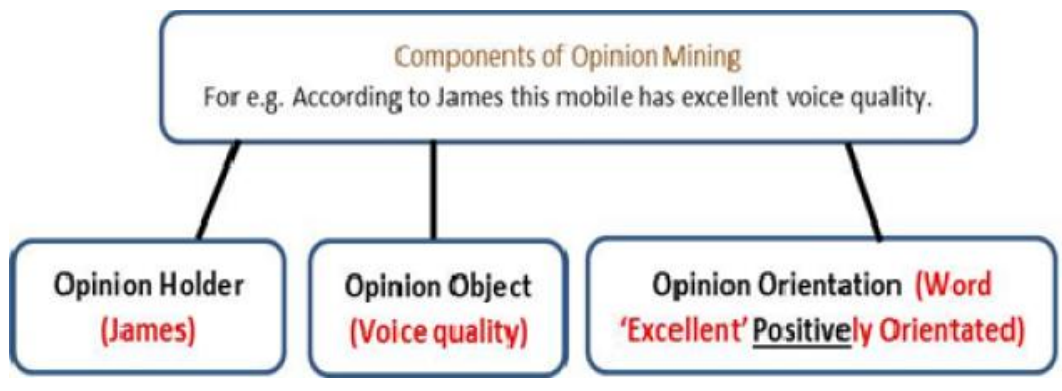

Figure 1. Components of opinion Mining

\section{Different Levels of Sentiment Analysis}

In general, sentiment analysis has been investigated mainly at three levels [4].

- Document level: The task at this level is to classify whether a whole opinion document expresses a positive or negative sentiment. For example, given a product review, the system determines whether the review expresses an overall positive or negative opinion about the product. This task is commonly known as document level sentiment classification.

- Sentence level: The task at this level goes to the sentences and determines whether each sentence expressed a positive, negative, or neutral opinion. Neutral usually means no opinion. This level of analysis is closely related to subjectivity classification which distinguishes sentences (called objective sentences) that express factual information from sentences (called subjective sentences) that express subjective views and opinions.

- Entity and Aspect level: Both the document-level and sentence-level analyses do not discover what exactly people liked and did not like. Aspect level performs fine-grained analysis. Aspect level was earlier called feature level (feature-based opinion mining and summarization).

\section{Challenges in Opinion Mining}

There are several challeges in Opinion Mining as follows, 
- Domain-independence: The biggest challenge faced by opinion mining and sentiment analysis is the domain dependent nature of sentiment words. One features set may give very good performance in one domain, at the same time it perform very poor in some other domain [5].

- Asymmetry in availability of opinion mining software: The opinion mining software is very expensive and currently affordable only to big organizations and government. It is beyond the common citizen's expectation. This should be available to all people, so that everyone gets benefit from it [6].

- Detection of spam and fake reviews: The web contains both authentic and spam contents. For effective Sentiment classification, this spam content should be eliminated before processing. This can be done by identifying duplicates, by detecting outliers and by considering reputation of reviewer [5].

- Incorporation of opinion with implicit and behavior data: For successful analysis of sentiment, the opinion words should integrate with implicit data. The implicit data determine the actual behavior of sentiment words [6].

- Mixed Sentences: Suppose the word is positive in one situation may be negative in another situation. For e.g. Word LONG, suppose if customer says the battery life of Samsung mobile is too long so that would be a positive opinion. But suppose if customer says that Samsung mobile take too long time to start or to charge so it would be a negative opinion.

- Way of Expressing the Opinion: The people don't always express opinions in the same way. The opinion of every individual is different because the way of thinking, the way of expressing is vary from person to person.

- Use of Abbreviations and shortforms: People using social media more and that to for chatting, expressing their views using shortcuts or abbreviations so the use of colloquial words is increased. Uses of abbreviation, synonyms, special symbols is also increase day by day so finding opinion from that is too difficult. For e.g. F9 for fine, thnx for thanks, u for you, b4 for before, b'coz for because, $\mathrm{h} r \mathrm{u}$ for how are you etc.

- Typographical Errors: Sometimes typographical errors cause problems while extracting opinions.

- Orthographics Words: People use orthographic words for expressing their excitement, happiness for e.g. Word Sooo.... Sweeetttt..... I am toooo Haappy or if they in hurry they stress the words for e.g. comeeee fassssssst I am waitttnggg.

- Natural language processing overheads: The natural language overhead like ambiguity, co-reference, Implicitness, inference etc. created hindrance in sentiment analysis too [6].

\section{Data Sources and Tools of Opinion Mining}

While doing research the collection of data is the biggest issue and for the task like opinion mining, sentiment analysis its too difficult because lots of information is available on internet and collection of that data and extraction of opinion from huge amount of data is too hard. So here we discussed about some available data sources and the tools which is used for extraction the sentiments and opinion of the given text.

\subsection{Data Sources Available for Opinion Mining}

There are various data sources available on web, i.e. Blogs, Microblogs, online posts, News feeds, Forums, review sites etc.

- Blogs: Blogs are nothing but the user own space or diary on internet where they can share their views, opinions about topics they want.

- Online Reviews: on Internet various review sites are available through that you can check online reviews of any product before purchasing that.

- Micro blogging: Microblogs allow users to exchange small elements of content such as short sentences, individual images, or video links", which may be the major reason for their popularity.

- Online Posts: people share their own ideas, opinions, photos, videos, views, likes, dislikes, comments on specific topics etc. 
- Forums: An Internet forum, or message board, is an online discussion site where people can hold conversations in the form of posted messages.

This table gives you an idea about the available data sources along with the address of sites from which you can download the posts, tweets, reviews for products etc.

Table 1. Available Data sources with web address

\begin{tabular}{|c|c|}
\hline Data Sources & Respective Sites/ Source \\
\hline Blogs & $\begin{array}{l}\text { http://indianbloggers.org/,http://www.bloggersideas.com/, } \\
\text { http://www.digitaltrends.com/,http://thoughts.com/free- } \\
\text { blog }\end{array}$ \\
\hline Review Sites & $\begin{array}{l}\text { http://www.sitejabber.com/,http://www.toptenreviews.com/, } \\
\text { http://www.trustedreviews.com/,https://in.pinterest.com, } \\
\text { http:///www.business-edge.com/,http://www.websitemagazine.com/, } \\
\text { http://www.yellowpages.com }\end{array}$ \\
\hline Micro-Blogging & $\begin{array}{l}\text { https://tumblr.com/(Tumblr),http://friendfeed.com/(Frendfeed), } \\
\text { http://www.plurk.com/top/(Plurk),https://twitter.com/(Twitter), } \\
\text { http://www.jaiku.com/(Jaiku),http://www.qaiku.com/(Quiku), } \\
\text { https://www.identi.ca/(Identica),http://www.spotjots.com/(Spotjots), } \\
\text { http://www.meetme.com/ (Meet me) }\end{array}$ \\
\hline Online Posts & $\begin{array}{l}\text { https://www.facebook.com/(Facebook),https://myspace.com/(MySpace), } \\
\text { http://www.skype.com/en/(Skype),https://www.linkedin.com/(Linkedin), } \\
\text { https://diasporafoundation.org/(Diaspora),https://plus.google.com/(Google } \\
\text { Plus),https://www.whatsapp.com/(Whatsapp),https://www.snapchat.com/ } \\
\text { (Snapchat),https://telegram.org/(Telegram),https://www.flickr.com/(Flickr) }\end{array}$ \\
\hline Forums & $\begin{array}{l}\text { http://www.forums.mysql.com,http://www.forums.cnet.com, } \\
\text { http://www.forum.joomla.org,https://forums.digitalpoint.com, } \\
\text { http://www.bookforum.com,http://www.myspace.com/forums, }\end{array}$ \\
\hline & $\begin{array}{l}\text { http://tsrmatters.com/(The Student Room), http://ubuntuforums.org/, } \\
\text { https://stackoverflow.com/, }\end{array}$ \\
\hline
\end{tabular}

\subsection{Tools Available for Opinion Mining}

As we discussed in 4.1 there are various data sources are available on web and mining those data is difficult task. Main difficulty is extraction of emotions, structure of text, form of data i.e. image or text, the language used on internet for communication is vary from person to person or state to state. So here are some ready to use tools for opinion mining for various purposes like data preprocessing, classification of text, clustering, opinion mining, sentiment analysis etc.

The table no. 2 shows the name of particular tool as well as uses of these tools.

Table 2. List of available tools

\begin{tabular}{|c|c|}
\hline Name of Tools & Uses \\
\hline STANFORD CORENLP [7] & $\begin{array}{l}\text { POS tagging, Named entity recognizer, Parsing, Coreference resolution } \\
\text { system, Sentiment analysis, Bootstrapped pattern learning }\end{array}$ \\
\hline WEKA [8] & $\begin{array}{l}\text { Machine learning algorithm for Data Mining, Data pre-processing, } \\
\text { Classification, Regression, Clustering, Association rules, Visualization. }\end{array}$ \\
\hline NLTK [9] & $\begin{array}{l}\text { Classification, Tokenization, Stemming, Tagging, Parsing, Semantic } \\
\text { reasoning, Provides lexical resources such as WordNet }\end{array}$ \\
\hline Apache Open NLP [10] & $\begin{array}{l}\text { Tokenization, Sentence segmentation, Part-of-speech tagging, Named } \\
\text { entity extraction, Chunking, Parsing, Coreference resolution }\end{array}$ \\
\hline LingPipe [11] & Entity extraction, POS tagging, Clustering, Classification. \\
\hline GATE [12] & $\begin{array}{l}\text { Tokenizer, Gazetteer, Sentence splitter, POS tagging, Named } \\
\text { entities transducer, Coreference tagger }\end{array}$ \\
\hline Pattern [13] & $\begin{array}{l}\text { Data mining, POS tagging, N-gram search, Sentiment analysis, WordNet, } \\
\text { Machine learning, Network analysis, Visualization }\end{array}$ \\
\hline $\begin{array}{l}\text { Robust Accurate Statistical } \\
\text { Parsing [14] }\end{array}$ & Statistical Parser, Tokenization, Tagging, Lemmatization and Parsing \\
\hline
\end{tabular}

\section{Existing Work in Opinion Mining}

As we know the beginning of opinion mining has marked in late 90's but this paper discusses the advances carried out from the year 2002 to 2014. In this section brief tabulated information about the major contribution in the field of opinion mining is shown. The table no. 3 
shows details about the author, their work, different techniques used while working on Opinion Mining and brief introduction of that paper as conclusion of that paper.

Table 3. List of available tools

\begin{tabular}{|c|c|c|c|c|c|}
\hline Ref. No. & Author's & Title of the Paper & $\begin{array}{c}\text { Techniques } \\
\text { used }\end{array}$ & Conclusion & Year \\
\hline [15] & $\begin{array}{l}\text { B. Pang, L. } \\
\text { Lee, } \quad \text { S. } \\
\text { Vaithyanathan }\end{array}$ & $\begin{array}{l}\text { Thumbs up? } \\
\text { Sentiment } \\
\text { Classification using } \\
\text { Machine Learning } \\
\text { Techniques }\end{array}$ & $\begin{array}{l}\text { Naïve Bayes, } \\
\text { Maximum } \\
\text { entropy } \\
\text { classification } \\
\text { and SVM }\end{array}$ & $\begin{array}{l}\text { In this paper, discussion on sentiment } \\
\text { classification of movie reviews on the basis } \\
\text { of positive and negative is given in length. } \\
\text { They used three different machine learning } \\
\text { algorithms for text classification for } \\
\text { increasing accuracy in classification. }\end{array}$ & 2002 \\
\hline [16] & Turney P.D & $\begin{array}{l}\text { Thumbs Up or } \\
\text { Thumbs Down? } \\
\text { Semantic } \\
\text { Orientation Applied } \\
\text { to Unsupervised } \\
\text { Classification of } \\
\text { Reviews }\end{array}$ & $\begin{array}{l}\text { Pointwise } \\
\text { mutual } \\
\text { information } \\
\text { (PMI) and } \\
\text { Information } \\
\text { Retrieval (IR) }\end{array}$ & $\begin{array}{l}\text { In this paper author classified reviews on } \\
\text { the basis of thumbs up(recommended) and } \\
\text { thumbs down (Not recommended) and } \\
\text { classification is predicted by semantic } \\
\text { orientation, for this purpose they used } \\
\text { unsupervised learning algorithm and PMI- } \\
\text { IR uses to measure the similarity of pairs } \\
\text { of words or phrases. }\end{array}$ & 2002 \\
\hline [17] & $\begin{array}{l}\text { Michael } \\
\text { Madden }\end{array}$ & $\begin{array}{l}\text { A New Bayesian } \\
\text { Network Structure } \\
\text { for Classification } \\
\text { Tasks }\end{array}$ & $\begin{array}{l}\text { Partial } \\
\text { Bayesian } \\
\text { Network } \\
\text { (PBN) } \\
\text { K2algorithm }\end{array}$ & $\begin{array}{l}\text { Author proposed a methodology for } \\
\text { induction of a Bayesian network structure } \\
\text { for classification and this structure is called } \\
\text { Partial Bayesian Network (PBN). It is } \\
\text { implemented using the K2 framework. } \\
\text { Learning the Partial Bayesian Network } \\
\text { essentially reduces to a Bayesian Network } \\
\text { learning problem using the K2 algorithm. } \\
\text { The complexity of K2 algorithm is } \\
\text { exponential to the number of variables; } \\
\text { hence, PBN is also feasible only for small } \\
\text { data sets. }\end{array}$ & 2002 \\
\hline [18] & $\begin{array}{ll}\text { Hai } & \text { Leong } \\
\text { Chieu, Hwee } \\
\text { Tou Ng }\end{array}$ & $\begin{array}{lr}\text { Named } & \text { Entity } \\
\text { Recognition: } & \text { A } \\
\text { Maximum Entropy } \\
\text { Approach Using } \\
\text { Global Information }\end{array}$ & $\begin{array}{l}\text { Maximum } \\
\text { Entropy }\end{array}$ & $\begin{array}{l}\text { In this paper authors presented maximum } \\
\text { entropy based named entity recognizer for } \\
\text { global information. It uses information from } \\
\text { the whole document to classify each word } \\
\text { with just one classifiers. }\end{array}$ & 2003 \\
\hline [19] & $\begin{array}{l}\text { Turney P.D., } \\
\text { Littman M.L }\end{array}$ & $\begin{array}{l}\text { Measuring praise } \\
\text { and criticism: } \\
\text { inference of } \\
\text { semantic orientation } \\
\text { from association. }\end{array}$ & $\begin{array}{l}\text { Pointwise } \\
\text { mutual } \\
\text { information } \\
\text { (PMI) and } \\
\text { Latent } \\
\text { semantic } \\
\text { analysis } \\
\text { (LSA) }\end{array}$ & $\begin{array}{l}\text { This paper introduced a method for } \\
\text { inferring the semantic orientation of a word } \\
\text { from its statistical association with a set of } \\
\text { positive and negative paradigm words.. } \\
\text { They use pointwise mutual information } \\
\text { (PMI) and latent semantic analysis (LSA) } \\
\text { to measure the relation between a word } \\
\text { and a set of positive or negative words and } \\
\text { according to this paper LSA gives better } \\
\text { results than PMI. }\end{array}$ & 2003 \\
\hline [20] & $\begin{array}{l}\text { S.-M. Kim, } \\
\text { E. Hovy }\end{array}$ & $\begin{array}{lr}\text { Determining } & \text { the } \\
\text { sentiment } & \text { of } \\
\text { opinions } & \end{array}$ & $\begin{array}{l}\text { SVM } \\
\text { (Support } \\
\text { Vector } \\
\text { Machine) }\end{array}$ & $\begin{array}{l}\text { Here author discusses about identifying } \\
\text { sentiments. Here classification and } \\
\text { combination of sentiment at word and } \\
\text { sentence levels for identifying opinion } \\
\text { holder they used learning techniques like } \\
\text { SVM. }\end{array}$ & 2004 \\
\hline [21] & $\begin{array}{l}\text { Soo-Min Kim, } \\
\text { Eduard Hovy }\end{array}$ & $\begin{array}{l}\text { Identifying Opinion } \\
\text { Holders for } \\
\text { Question Answering } \\
\text { in Opinion Texts }\end{array}$ & $\begin{array}{l}\text { Maximum } \\
\text { Entropy }\end{array}$ & $\begin{array}{l}\text { In this paper they used Maximum Entropy } \\
\text { for learning the opinion holders } \\
\text { automatically with the help of two ways i.e. } \\
\text { Classification and Ranking. }\end{array}$ & 2005 \\
\hline [22] & $\begin{array}{l}\text { Jack G. } \\
\text { Conrad, Frank } \\
\text { Schilder }\end{array}$ & $\begin{array}{l}\text { Opinion Mining in } \\
\text { Legal Blogs }\end{array}$ & $\begin{array}{l}\text { Language } \\
\text { Model and } \\
\text { Naive Bayes } \\
\text { classifiers. }\end{array}$ & $\begin{array}{l}\text { Here in this paper authors discuss about } \\
\text { the scope and opinion mining of blogs } \\
\text { which is increased in legal domain. Here } \\
\text { they first construct a Weblog test collection } \\
\text { containing blog entries that discuss legal } \\
\text { search tools. Then they subsequently } \\
\text { examine the performance of a language } \\
\text { modeling approach deployed for both } \\
\text { subjectivity analysis and polarity analysis. }\end{array}$ & 2007 \\
\hline
\end{tabular}

IJEEI Vol. 4, No. 2, June 2016 : $141-148$ 


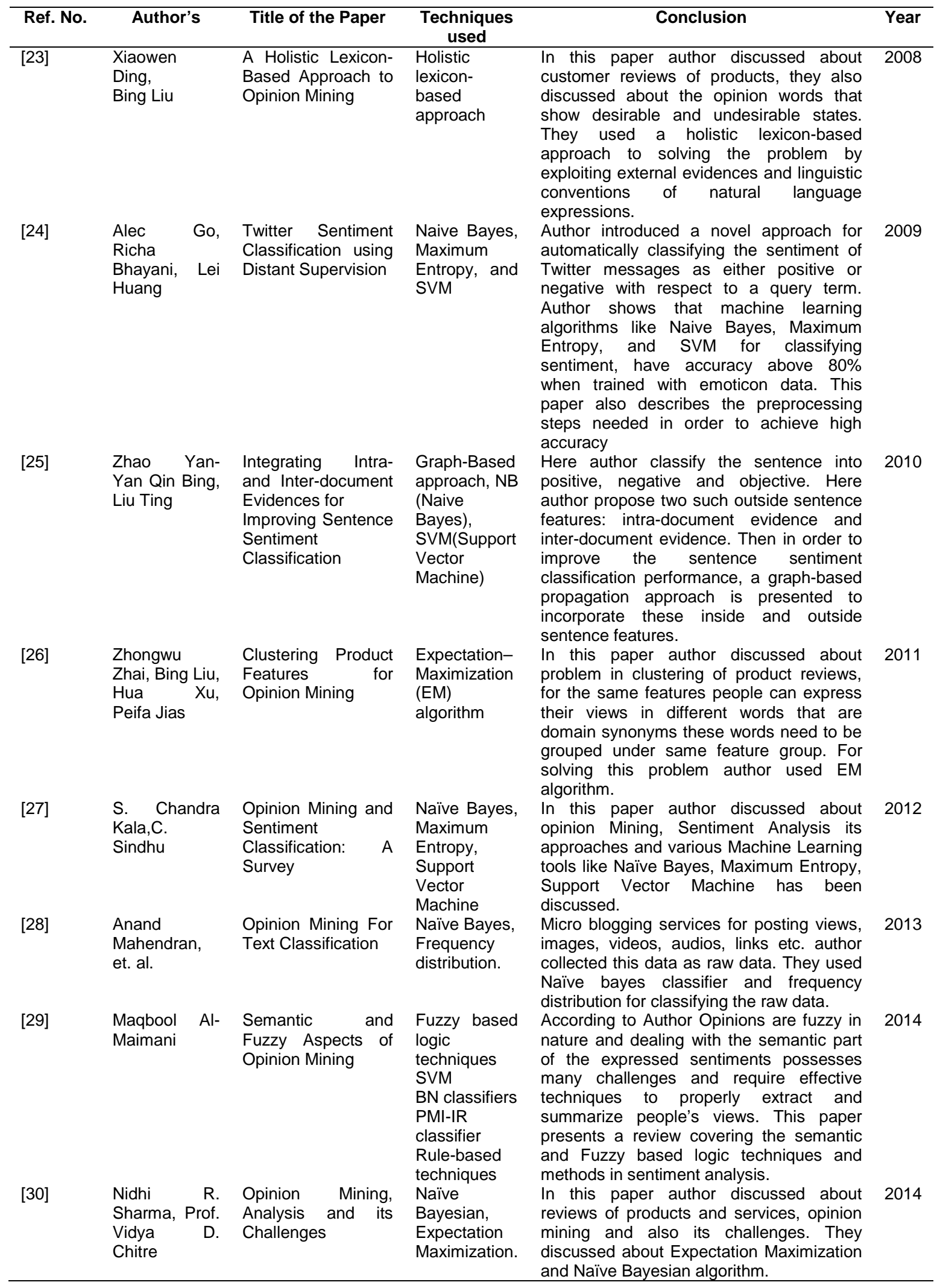

The above table information suggest that statistical techniques have been used mostly used by the researchers for extracting or mining the opinions. 


\section{Conclusion}

Emotions are often associated and considered commonly significant with mood, nature, personality, disposition, and motivation. Opinion Mining or Sentiment analysis refers to extraction of opinion from given text and classify them on the basis of polarity i.e. positive, negative and neutral. In this paper, we discussed about various levels of sentiment analysis and technique used to identify and extract opinions. Here we gave some challenges used while working on opinion mining like some orthographic errors, typographical mistakes, abbreviations, colloquial words etc. are the major challenges. This paper provides a brief review to cover the major challenges, stages, application and advantages of opinion mining. In our study, we find some techniques like Naive Bayes, Maximum Entropy, SVM etc. are very oftenly used in opinion mining and sentiment analysis.

\section{Acknowledgements}

We are thankful to the Computational and Psycho-linguistic Research Lab, Dept. of Computer Science \& Information Technology, Dr Babasaheb Ambedkar Marathwada University, Aurangabad (MS) for providing the facility for carrying out the research.

\section{References}

[1] Cacioppo. "Studyguide for Discovering Psychology: The Science of Mind". John Publication. 2014.

[2] S Chandra Kala and C Sindhu. "Opinion Mining and Sentiment Classification: A Survey". ICTACT Journal On Soft Computing. 2012; 03(01).

[3] Sharma R et al. "Opinion Mining in Hindi Language: A Survey". International Journal in Computer Science \& Technology(IJFCST). $2014 ; 4$ (2).

[4] Bing L. "Sentiment Analysis and Opinion Mining". Morgan \& Claypool Publishers. 2012.

[5] Liu B. "Sentiment Analysis and Subjectivity". Appeared in Handbook of Natural Language Processing, Indurkhya, N. \& Damerau, F.J. [Eds.]. 2010.

[6] Haseena Rahmath. "Opinion Mining and Sentiment Analysis - Challenges and Applications". International Journal of Application or Innovation in Engineering \& Management (IJAIEM). 2014; 3(5).

[7] http://nlp.stanford.edu/software/corenlp.html

[8] http://www.cs.waikato.ac.nz/ml/weka/

[9] http://www.nltk.org/

[10] https://opennlp.apache.org/

[11] http://alias-i.com/lingpipe/

[12] https://gate.ac.uk/

[13] http://www.clips.ua.ac.be/pattern

[14] http://www.sussex.ac.uk/Users/johnca/rasp/offline-demo.html

[15] B Pang, L Lee and S Vaithyanathan. "Thumbs up? Sentiment classification using machine learning techniques". Proceedings of the Conference on Empirical Methods in Natural Language Processing. 2002: 79-86.

[16] Turney PD. "Thumbs up or down? Semantic orientation applied to unsupervised classification of reviews". 2002 ACL. 2002: 417-424.

[17] MG Madden. "A new Bayesian network structure for classification tasks". Proceedings of 13th Irish Conference on Arti ficial Intelligence \& Cognitive Science. 2002;. 2464.

[18] Hai Leong Chieu et al. "Named Entity Recognition: A Maximum Entropy Approach Using Global Information". http://www.cnts.ua.ac.be/conll2003/pdf/16063chi.pdf

[19] Turney PD, Littman ML. "Measuring praise and criticism: Inference of semantic orientation from association". ACM TOIS. 2003; 21(4): 315-346.

[20] SM Kim and E Hovy. "Determining the sentiment of opinions". Proceedings COLING-04, the Conference on Computational Linguistics, Geneva, Switzerland. 2004.

[21] SM Kim and E Hovy. "Identifying opinion holders for question answering in opinion texts". Proceedings of AAAI Workshop on Question Answering in Restricted Domains. 2005: 20-26.

[22] Jack G Conrad and Frank Schilder. "Opinion Mining in Legal Blogs". ACM,ICAIL '07. 2007.

[23] Xiaowen Ding, Bing Liu. "A Holistic Lexicon-Based Approach to Opinion Mining". ACM WSDM'08. 2008.

[24] Alec Go, Richa Bhayani, Lei Huang. "Twitter sentiment classification using distant supervision". CS224N Project Report, Stanford. 2009.

[25] Zhao Yan-Yan, Qin Bing, Liu Ting. "Integrating Intra- and Inter-document Evidences for Improving Sentence Sentiment Classification". ACTA AUTOMATICA SINICA-Elsevier. 2010.

[26] Zhongwu Zhai et al. "Clustering Product Features for Opinion Mining", WSDM'11 Hong Kong, China. 2011. 
[27] S Chandra Kala, C Sindhu. "Opinion Mining and Sentiment Classification: A Survey". ICTACT Journal on Soft Computing. 2012; 03(01).

[28] Anand Mahendran. "Opinion Mining For Text Classification". International Journal of Scientific Engineering and Technology (ISSN : 2277-1581). 2013; 2(6): 589-594.

[29] Maqbool Al-Maimani et al. "Semantic and Fuzzy Aspects of Opinion Mining". Journal of Theoretical and Applied Information Technology. 2014; 63(2).

[30] Nidhi R Sharma et al. "Opinion Mining, Analysis and its Challenges". International Journal of Innovations \& Advancement in Computer Science IJIACS ISSN 2347 - 8616. 2014; 3(1). 